\title{
Spatiotemporal dynamics of fog and low clouds in the Namib unveiled with ground- and space-based observations
}

\author{
Hendrik Andersen ${ }^{1,2}$, Jan Cermak ${ }^{1,2}$, Irina Solodovnik ${ }^{1,2}$, Luca Lelli ${ }^{3}$, and Roland $\operatorname{Vogt}^{4}$ \\ ${ }^{1}$ Karlsruhe Institute of Technology (KIT), Institute of Meteorology and Climate Research, Karlsruhe, Germany \\ ${ }^{2}$ Karlsruhe Institute of Technology (KIT), Institute of Photogrammetry and Remote Sensing, Karlsruhe, Germany \\ ${ }^{3}$ University of Bremen, Institute of Environmental Physics and Remote Sensing, Bremen, Germany \\ ${ }^{4}$ University of Basel, Department of Environmental Sciences, Basel, Switzerland
}

Correspondence: Hendrik Andersen (hendrik.andersen@kit.edu)

Received: 6 December 2018 - Discussion started: 17 December 2018

Revised: 21 March 2019 - Accepted: 22 March 2019 - Published: 4 April 2019

\begin{abstract}
Fog is an essential component of Namib-region ecosystems. Current knowledge on Namib-region fog patterns and processes is limited by a lack of coherent observations in space and time. In this study, data from multiple satellite platforms and station measurements paint a coherent picture of the spatiotemporal dynamics of fog and low cloud (FLC) distribution. It is found that observed seasonal FLC patterns derived from satellite observations differ from fog measurements at coastal station locations, whereas they agree further inland. This is linked to an observed seasonal cycle in the vertical structure of FLCs that determines the probability of low-level clouds touching the ground. For the first time, these observations are complemented by spatially coherent statistics concerning the diurnal cycle of FLCs using geostationary satellite data. The average timing of the start of the diurnal FLC cycle is found to strongly depend on the distance to the coastline (correlation $\approx 0.85$ north of $25^{\circ} \mathrm{S}$ ), a clear indication of dominant advective processes. In the central Namib, FLCs typically occur $2-4 \mathrm{~h}$ later than in other coastal regions, possibly due to local advection patterns. The findings lead to a new conceptual model of the spatiotemporal dynamics of fog and low clouds in the Namib.
\end{abstract}

\section{Introduction}

In arid environments like the Namib, fog can be a crucial source of water for many species and ecosystems (e.g., Seely et al., 1977; Seely, 1979; Shanyengana, 2002; Ebner et al., 2011; Azúa-Bustos et al., 2011; Roth-Nebelsick et al., 2012;
Eckardt et al., 2013; McHugh et al., 2015). However, only little is known about its spatial and temporal patterns, as well as the environmental drivers of fog in the Namib.

While meteorological measurements are generally sparse in this region, historical station observations of fog in the central Namib between the 1940s and the 1980s have shown contrasting seasonal patterns of fog occurrence at coastal and inland locations (Nagel, 1959; Lancaster et al., 1984). These studies find that, at inland locations, fog tends to occur less frequently between April and August, while fog occurrence at coastal locations peaks during this time. More recently, satellite data have been used to study the patterns of fog and low clouds (FLCs) in the Namib (e.g., Olivier, 1995; Cermak, 2012; Andersen and Cermak, 2018). The only satellite-based study that comprises a multi-year seasonal cycle of FLCs is presented in Cermak (2012), and while the observed patterns compare well to station measurements of fog presented in Lancaster et al. (1984) at the inland station in Gobabeb, observed seasonal cycles from satellite data and station measurements of fog differ at the coastal location in Walvis Bay. This could be related to seasonally varying mechanisms responsible for fog formation or due to a seasonal cycle in vertical characteristics of FLCs in this region, i.e., the fact that all low clouds are treated summarily by the satellite technique, whereas only the ones with the lowest cloud bases manifest themselves as fog as reported by ground-based observations. However, a spatially coherent detailed characterization of FLCs, including vertical characteristics, as well as seasonal and diurnal patterns, is still missing. Additionally, the importance of the different 
mechanisms that can lead to fog formation is still uncertain. While most studies (e.g., Lancaster et al., 1984; Olivier and Stockton, 1989; Olivier, 1992, 1995; Cermak, 2012; Andersen and Cermak, 2018) relate Namib-region fog mostly to the advection of low clouds formed over the cool waters of the Benguela current, recent analyses of stable isotopes have pointed to mixed or sweet water sources, which have been interpreted as an indication for radiation fog (Kaseke et al., 2017, 2018). However, the labor-intensive field work needed for isotope analyses has limited these studies in spatial and temporal extent, underscoring the need for a spatiotemporally complete and coherent characterization of FLC mechanisms. In this study, active-sensor and passive-sensor satellite data are used in conjunction with ground-based meteorological measurements to better understand fog and low-cloud patterns at different scales. The goal of this study is to provide climatological, spatiotemporally complete patterns that help understand the processes driving Namib-region fog and low clouds.

The guiding hypotheses are that

1. FLC patterns in time and space differ distinctly between the coastline and regions further inland, and

2. apparent differences between the seasonal cycle of fog as observed from the ground and satellite perspectives are explained by a seasonal cycle in the vertical structure of FLCs.

\section{Data and methods}

In this study, multiple data sets from various space-based sensors are used to characterize FLCs and analyze their spatiotemporal occurrence patterns. The general spatial domain investigated in this study is the western coastline of southern Africa $\left(13.5-34^{\circ} \mathrm{S}\right.$ and 5-20 $\mathrm{E}$, Fig. 1a), with a specific focus on patterns over land and a core region of FLC occurrence in the central Namib near Walvis Bay $\left(22.5-24^{\circ} \mathrm{S}\right.$ and $\approx 14-15.5^{\circ}$ E, Fig. 1b). In the central Namib, the FogNet station network (Kaspar et al., 2015) is located, providing a ground-based perspective on fog patterns. Detailed descriptions of the different sensors, techniques and data sets used in this study are given in Sect. 2.1-2.4.

\subsection{SEVIRI}

Coherent spatiotemporal patterns of FLC occurrence are created using data from the Spinning Enhanced Visible and Infrared Imager (SEVIRI) aboard the Meteosat Second Generation (MSG) satellites. The sensor has a nadir spatial resolution of $3 \mathrm{~km}$ and provides 96 hemispheric scans per day (repeat rate of $15 \mathrm{~min}$ ) (Schmetz et al., 2002). The novel FLCdetection technique by Andersen and Cermak (2018) is applied to data of nearly the entire operational period of MSG satellites (2004-2017). The technique uses only observations (a)

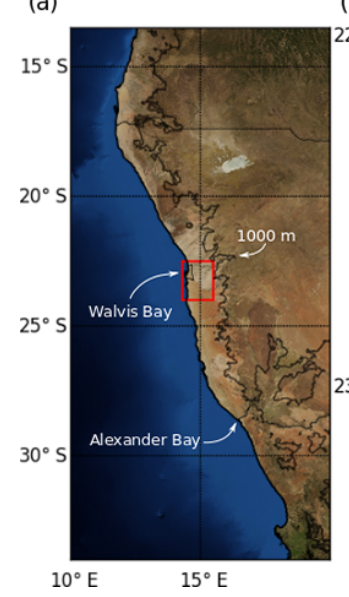

(b)

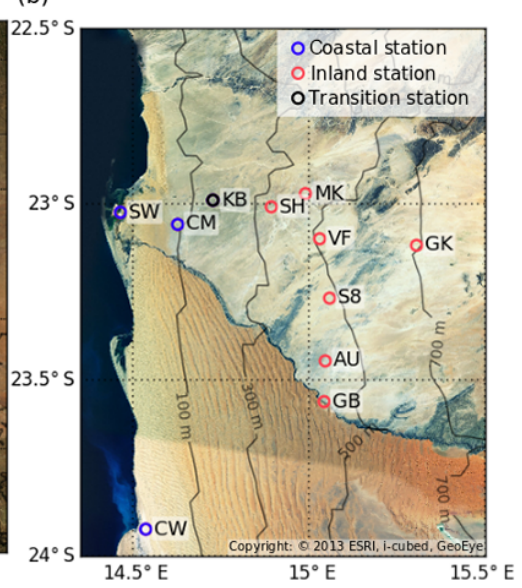

Figure 1. (a) An overview of the study area. The grey line represents $1000 \mathrm{~m}$ above sea level and approximates the transition from the low-lying coastal plains to the Great Escarpment that represents the eastern limit of the Namib desert. The red box in the Walvis Bay area highlights the central Namib, which is shown in more detail in panel (b): FogNet stations are illustrated by circles and are annotated with their respective IDs (full station names are given in the Appendix). Blue circles represent coastal and red circles inland stations as defined in this study (Sect. 2.4). The Kleinberg (KB) station is colored in black, as it is viewed to be at a transitional location not clearly belonging to either category.

in the thermal infrared, enabling a fully diurnal detection of FLCs in the region. It has been validated against surface net radiation measurements with a probability of detection of $94 \%$, a false alarm rate of $12 \%$ and a general correctness of all classifications of $97 \%$ (Andersen and Cermak, 2018).

\subsection{CALIPSO}

SEVIRI observations are complemented by retrieved layer heights from the active-sensor platform from the CloudAerosol Lidar and Infrared Pathfinder Satellite Observation (CALIPSO). Mounted aboard the satellite is the CloudAerosol Lidar with Orthogonal Polarization (CALIOP) that samples with $30 \mathrm{~m}$ vertical and $333 \mathrm{~m}$ horizontal resolutions. Here, the level 2 CALIPSO $5 \mathrm{~km}$ cloud-layer product (version 4.10) is used to detect FLCs with the algorithm developed by Cermak (2018) for the period of 13 June 200631 December 2017 (daytime and nighttime). The algorithm essentially detects low clouds with a cloud-top altitude of $\leq 2000 \mathrm{~m}$ and a cloud-base altitude $\leq 500 \mathrm{~m}$ above ground level. Additionally, spatial and temporal patterns of cloud-top height (CTH) are generated using the same data. Results are then aggregated to $2.5^{\circ} \times 2.5^{\circ}$ regions to increase the sample size as in Cermak (2018). 


\subsection{SCIAMACHY}

The Scanning Imaging Absorption Spectrometer for Atmospheric Chartography (SCIAMACHY) sensor (Bovensmann et al., 1999), aboard the Envisat platform, is used to infer cloud bottom altitudes. This is done using the fit of sunlight absorption by the strongest molecular band of oxygen (the A band), located in the near-infrared (NIR) between 750 and $770 \mathrm{~nm}$ (nominal spectral resolution $0.4 \mathrm{~nm}$ ). The deployed algorithm Semi-Analytical CloUd Retrieval Algorithm (SACURA) (Rozanov and Kokhanovsky, 2004; Lelli et al., 2012) exploits the constant vertical abundance of columnar oxygen so that any cloud intervening in the field of view of the sensor shields the gas column below, thus changing the depth of the A band. Concurrently, the increase of absorption by oxygen within a cloud due to multiple scattering is accounted for by calculating the single-scattering albedo of the atmospheric volume at $760 \mathrm{~nm}$. In this way, with the knowledge of the cloud optical thickness (COT) computed at the non-absorbing channel $(758 \mathrm{~nm})$, the inversion of the measurement delivers the cloud geometrical extent. As long as the sensed cloud is single layered and has a constant liquid water content, the reported model error in $\mathrm{CBH}$ amounts to $-200 / 350 \mathrm{~m}$ (Lelli et al., 2011), which is paired to a CTH absolute error of $\pm 250 \mathrm{~m}$ (Lelli et al., 2012, 2014). These errors are irrespective of COT, given CTH values $<10 \mathrm{~km}$. However, the coarse footprint size of SCIAMACHY $(60 \times 40 \mathrm{~km}$ at nadir) can degrade this assumption due to a likely heterogeneous cloud field sensed by the instrument. In this case, a set of filters ensures the extraction of a representative cloud sample from the unfiltered data record, discarding cirrus and multi-layer clouds. The procedure employed here is extensively described in Lelli and Vountas (2018) and 7 years (2003-2009) of retrievals at the SCIAMACHY overpass of $\approx 10: 15 \mathrm{LT}$ are aggregated monthly at a grid resolution of $0.5^{\circ}$.

\subsection{Ground-based measurements}

Overall, 3 years (2014-2017) of station measurements from the FogNet station network in the central Namib are used to gain insights into fog occurrence at the ground. As illustrated in Fig. 1b, the FogNet network consists of 11 automated meteorological stations that are aligned in two transects $(\mathrm{N}-\mathrm{S}$ from 22.97 to $23.92^{\circ} \mathrm{S}$ and $\mathrm{W}-\mathrm{E}$ from 14.46 to $15.31^{\circ} \mathrm{E}$ ). FogNet was created as part of the Southern African Science Service Centre for Climate Change and Adaptive Land Management (SASSCAL) initiative to study fog occurrence and processes in this region (Kaspar et al., 2015). The stations can be broadly classified by their geographic location into low-lying coastal stations (blue circles in Fig. 1b): all stations located $<100 \mathrm{~m}$ above sea level (a.s.l.); and inland stations (red circles in Fig. 1b): all stations located $>300 \mathrm{~m}$ a.s.1.), as well as a transition station (Kleinberg: KB).
Measurements of fog precipitation and relative humidity are combined to create a binary data set of fog occurrence. Fog precipitation measurements describe advected cloud water collected by a Juvik fog collector (Juvik and Nullet, 1995). The Juvik fog collector is an omnidirectional, cylindrical aluminium fog gauge, positioned at $1.5 \mathrm{~m}$ above ground. Measured fog precipitation depends on the nearground liquid water content of fog and fog droplet size, and also scales with near-surface wind speed, as this determines the volume of air that perfuses the gauge (Frumau et al., 2011). There can be a time lag between fog occurrence and measured fog precipitation due to the build-up time until the runoff of fog water occurs. Also, the instrument might not be sensitive in instances of very thin fog, as there is a lower limit of water needed for runoff. To reduce measurement-related uncertainties in the fog occurrence estimates, fog precipitation measurements are supplemented by observations of $2 \mathrm{~m}$ relative humidity (Campbell CS215) to create a binary fog product. The station measurements have a 1 min temporal resolution but are averaged in 15 min intervals for comparison with SEVIRI observations. Fog is counted whenever the average relative humidity during a $15 \mathrm{~min}$ interval exceeds $95 \%$ or any amount of fog precipitation is measured during this time.

A ceilometer (Vaisala CL31, instrument "CL31-2" in Wiegner et al., 2019) complemented the measurements at the Coastal Met (CM) station from September 2017 to June 2018 to observe patterns in cloud-base height (CBH). In July, the ceilometer was repositioned closer to the coastline (Swakopmund). The CL31 emits a laser beam at $905 \mathrm{~nm}$ and provides a profile of attenuated light backscatter with a vertical resolution of up to $5 \mathrm{~m}$ (Martucci et al., 2010; Kotthaus et al., 2016). It emits $2^{14}$ laser pulses with a frequency of $10 \mathrm{kHz}$ every $2 \mathrm{~s}$, after which it takes about $0.36 \mathrm{~s}$ of idle time to compute the cloud-base height (Vaisala CL31 firmware) (Kotthaus et al., 2016). CBH retrievals are then averaged to a temporal resolution of $1 \mathrm{~min}$. This CL31 has a minimum detection altitude of $\approx 40 \mathrm{~m}$ and was located at $\approx 95 \mathrm{~m}$ a.s.l. at $\mathrm{CM}$ and is currently situated at $\approx 19 \mathrm{~m}$ a.s.l. at Swakopmund. As such, the ceilometer cannot give an accurate estimate for $\mathrm{CBH}<135 \mathrm{~m}$ a.s.1. or $59 \mathrm{~m}$, respectively. Here, data from 1 year (September 2017 to August 2018) are used. Due to data collection difficulties, no data are available during February 2018. To focus on fog and low-level clouds, only $\mathrm{CBH}<2000 \mathrm{~m}$ a.g.l. are considered.

\section{Results and discussion}

\subsection{Fog and low cloud spatial patterns and seasonality}

Figure 2 shows climatological patterns of FLC occurrence as seen by CALIPSO (Fig. 2a) and SEVIRI (Fig. 2b) using the algorithms developed by Cermak (2018) (land and ocean) and Andersen and Cermak (2018) (land only), respectively. 
(a)

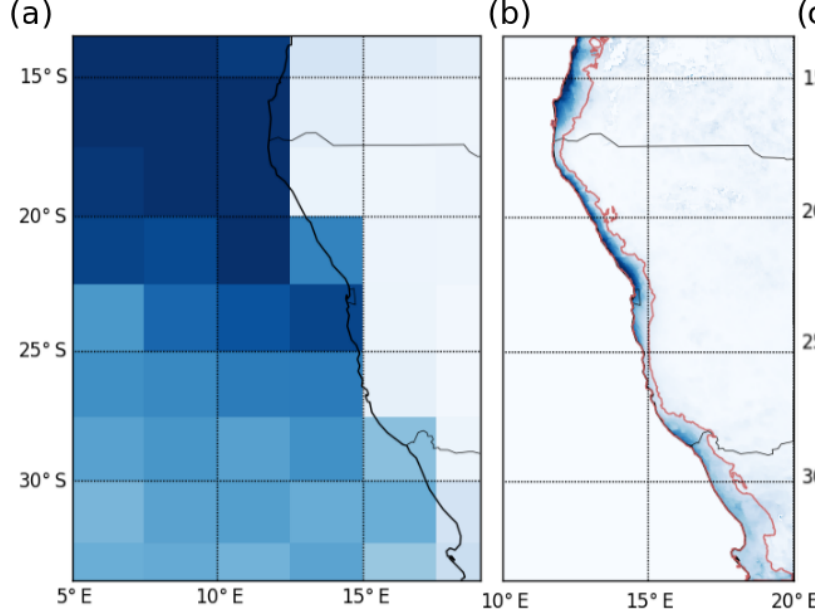

(c)

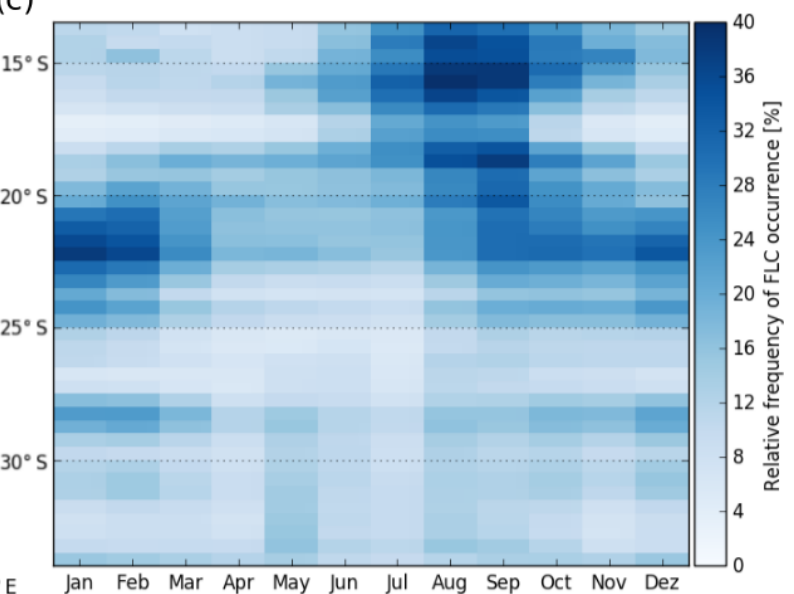

Figure 2. A satellite-based climatology of relative fog and low cloud occurrence frequency derived by using the algorithms presented in Cermak (2018) (a) and Andersen and Cermak (2018) (b), based on the nearly complete data records of CALIPSO (2006-2017) and SEVIRI (2004-2017). Daytime and nighttime overpasses (approximately 13:00 and 01:00 UTC, respectively) are averaged to produce panel (a); all SEVIRI time slots are used for panel (b). The seasonality (c) is computed by averaging pixels from panel (b) in coastal regions (maximum $100 \mathrm{~km}$ distance to coastline) with frequent FLC occurrence (minimum of $5 \%$ relative FLC occurrence in the 14-year climatology shown in panel b). The regions used for averaging in panel (c) lie within the red contours in panel (b).

The spatial patterns of FLC occurrence correspond well with those derived in earlier satellite-based studies (Olivier, 1995; Cermak, 2012; Andersen and Cermak, 2018), where FLCs occur frequently over the ocean and in the low-lying coastal plains, with three separate core regions over land: the southern parts of the Angolan coastline $\left(15-17^{\circ} \mathrm{S}\right)$, the Namibian coastline from Walvis Bay $\left(\approx 23^{\circ} \mathrm{S}\right)$ northwards to $18^{\circ} \mathrm{S}$ and to a lesser extent at Alexander Bay at the NamibianSouth African border $\left(\approx 28^{\circ} \mathrm{S}\right)$. While not studied here in detail, smaller spatial structures of FLC occurrence may be influenced by local topography, e.g., by river valleys that can lead to a channeling of the inland flow and locally higher humidity levels (Olivier, 1995). The general spatial patterns of FLC occurrence (Fig. 2a, b) indicate a connection between the stratocumulus cloud field off the southwestern African coastline and FLC occurrence in the Namib, even though the CALIPSO data are not able to capture some of the finer spatial features in FLC distribution (e.g., the low-FLC region between 17 and $18^{\circ} \mathrm{S}$ ) due to the coarse averaging resolution. The occurrence of FLCs along the western coast of southern Africa features a distinct seasonal cycle that varies with latitude (Fig. 2c) and agrees with findings from Cermak (2012). The observed seasonal pattern of the Angolan Namib agrees well with that of the southeastern Atlantic stratocumulus cloud field (Klein and Hartmann, 1993) and underscores a likely link of stratocumulus clouds over the ocean and FLCs over land. The latitudinal dependence of the seasonal patterns of FLCs may be an indication of a seasonal shift of the large-scale dynamical systems responsible for a landward advection of low clouds formed over the ocean. It is likely that the position and strength of the Atlantic and mid- continental high-pressure systems as well as the Intertropical Convergence Zone combine to drive the observed seasonal patterns of FLCs.

The satellite-derived seasonal cycle of FLC occurrence agrees well qualitatively and quantitatively with the seasonality of fog observed at inland stations (Fig. 3b). However, the observations do not show similar patterns at the coastal stations (Fig. 3a). Here, satellite observations show a seasonality that resembles that found at inland stations, with a minimum during May and a maximum in September. In contrast, ground-based fog observations at the coastal stations peak in winter between April and August. This mismatch between ground-based fog measurements and space-based FLC observations is also apparent when comparing earlier studies by Lancaster et al. (1984) and Cermak (2012). It should be noted that while the seasonal patterns disagree, during the period from April to July, observed fog/FLC occurrence frequencies agree quantitatively (Fig. 3b). Both - similarities and discrepancies of the observed seasonal cycles - are likely explained in large parts by the seasonality in the vertical structure of FLCs in the central Namib (Fig. 3b). Cloud vertical properties are investigated using ground-based and spacebased active sensoric measurements. A distinct seasonal pattern in CTH is observed using CALIPSO, with $183 \mathrm{~m}$ lower cloud-top altitudes between April and June compared to the rest of the year (significant at the $99 \%$ confidence level: independent $t$ test). This seasonal pattern is also found in observations of CBH of the CL31 ceilometer located in CM. Here, cloud bases are found to be on average $130 \mathrm{~m}$ lower between April and June than during the rest of the year. As the ceilometer measurements are only available for 1 (in- 
(a)

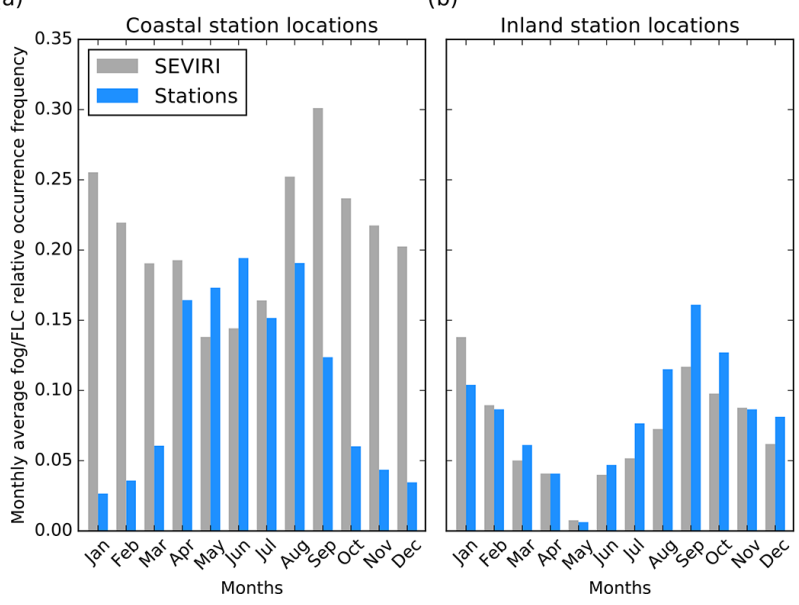

(c)

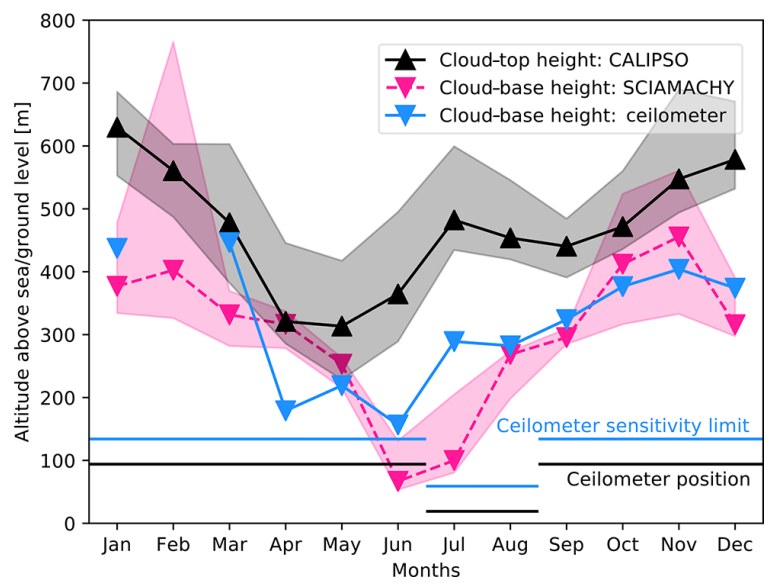

Figure 3. Monthly averaged relative fog/FLC occurrence frequency at locations of coastal (a) and inland stations (b) as defined in Fig. 1b. SEVIRI observations (2004-2017) are illustrated by grey bars; station measurements of ground fog (2015-2017) are in blue. (c) Medians, 25th and 75th percentiles of monthly averaged CBH and CTH in the central Namib based on SCIAMACHY (above ground level; 22.5-24.0 $0^{\circ}$ and $14.25-15.5^{\circ} \mathrm{E} ; 2003-2009$ ) and CALIPSO (above sea level; 22.5-24.0 $0^{\circ} \mathrm{S}$ and 14.0-15.5 E; 2006-2017) observations, respectively. Ceilometer $\mathrm{CBH}$ observations (above sea level) are only available starting from September 2017. Ceilometer positions (Coastal Met from September to June and Swakopmund in July and August) and sensitivity limits are illustrated by thin horizontal lines and described in Sect. 2.4.

complete) year, 7-year monthly averaged CBH estimates from SCIAMACHY are considered in addition. While the SCIAMACHY-derived $\mathrm{CBH}$ are especially low later in the year (June and July), the seasonal pattern agrees in the sense that it features lower $\mathrm{CBH}$ during the southern-hemispheric winter (CBH $173 \mathrm{~m}$ lower in June, July and August than during all other months, significant at the $95 \%$ confidence level: independent $t$ test). It is likely that during this time, FLCs touch the ground even at the low-lying coastal stations (located on average $\approx 40 \mathrm{~m}$ above sea level) frequently, leading to the observed agreement between ground fog and satellitebased FLCs during this time (Fig. 3a). Between August and March, cloud-base height is significantly higher on average and displays a higher variability, more frequently leading to situations where clouds are disconnected from the surface at the coast but still might touch the ground further inland, leading to fog occurrences at stations located there (locations on average $\approx 490 \mathrm{~m}$ above sea level).

\subsection{Diurnal cycle of fog and low clouds}

Based on the diurnally stable FLC detection by Andersen and Cermak (2018), spatial information on the statistical properties of the diurnal cycle of FLCs can be analyzed. Figure 4a shows the average time of day when the FLC diurnal cycle typically starts. The start of the diurnal cycle is defined here as the first occasion after the diurnal FLC minimum during noon, when the relative FLC occurrence frequency reaches $10 \%$ of the total range of its diurnal cycle at this location and is derived from 14 years of SEVIRI observations. To focus on the regions where FLCs frequently occur, pixels are only considered if they are located within $100 \mathrm{~km}$ to the coastline and feature a relative frequency of FLC occurrence of at least $5 \%$. It is apparent from Fig. 4a that the start of the diurnal FLC cycle is closely related to the distance from the coastline, at least north of $25^{\circ} \mathrm{S}(r=0.86$ between 22.5 and $25^{\circ} \mathrm{S}$ and $r=0.85$ north of $22.5^{\circ} \mathrm{S}$ ). As Andersen and Cermak (2018) argue, this is a clear indication of a region dominated by advective processes rather than radiation fog, contrasting findings from Kaseke et al. (2017). It should be noted that while the results here are of statistical nature and thus reflect the dominant patterns, incidences of radiation fog are also likely to occur, at least in some locations. The apparent discrepancy between these findings might be related to the limited sampling of the isotope analyses or due to a mixing of water from marine and continental sources as water vapor from local sources is additionally condensed at the front of the advected cold marine stratus.

More distinct spatial characteristics in the start time of the diurnal FLC cycle can be identified, as in the region between 22.5 and $25^{\circ} \mathrm{S}$ (circles in Fig. 4b), FLCs typically start to occur more than $2 \mathrm{~h}$ later than in other regions along the southwestern African coastline. This temporal offset may be due to local advection patterns, as fog at the inland station Gobabeb (GB) has been found to be associated with northwesterly wind (Seely and Henschel, 1998), as opposed to a direct westerly advection from the coast. The timing of FLC occurrence may also be locally modified by surface characteristics, e.g., increased surface roughness due to the coastparallel linear dunes of the Namib sand sea $(\approx 100 \mathrm{~m}$ high; Vermeesch et al., 2010) that may decelerate the inland advection of FLCs. 
(a)

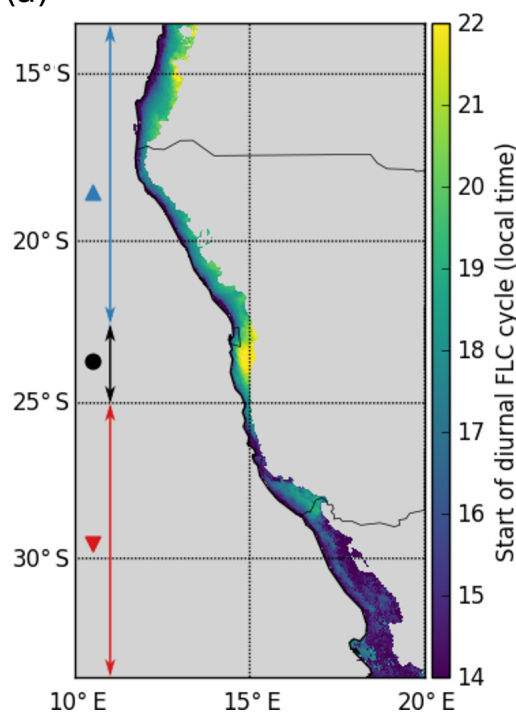

(b)

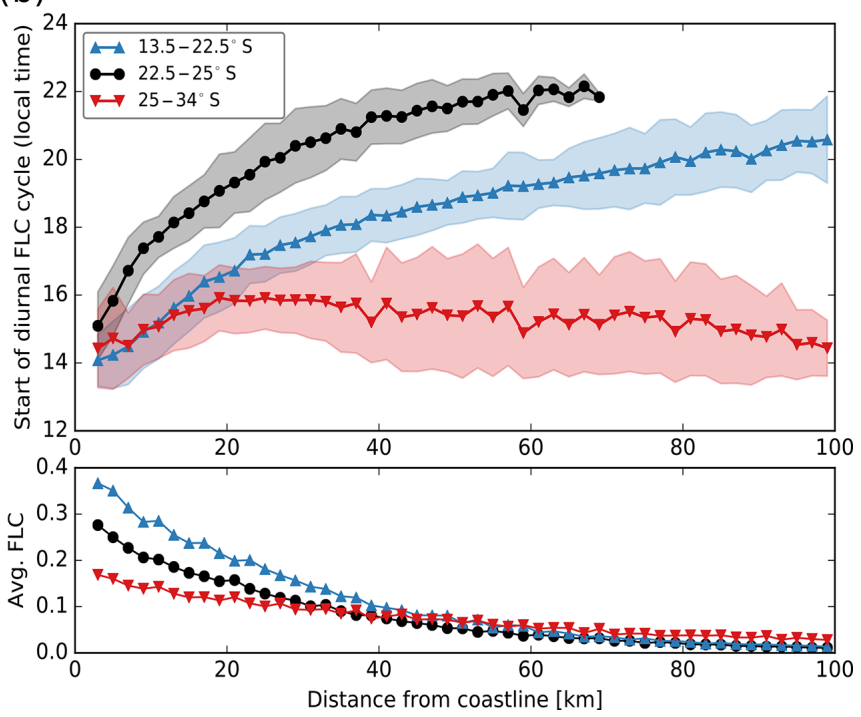

Figure 4. (a) The time of the start of the diurnal FLC cycle on pixel level. Pixels which are either more than $100 \mathrm{~km}$ removed from the coastline or feature a relative frequency of FLC occurrence of less than $5 \%$ are not considered. The north-south-oriented arrows indicate the northern/southern extent of the three regions considered in panel (b), with colored markers illustrating their respective association. (b) Upper panel: the average timing of start of the diurnal FLC cycle as a function of average distance to the coastline. Shaded area illustrates mean \pm 1 standard deviation. Lower panel: average relative FLC occurrence frequency in the three subregions. The same pixels are considered as in panel (a) and are averaged in $2 \mathrm{~km}$ distance bins ( $x$ axis).

The differences in timing between the three subregions in Fig. 4 are highly significant (99\% confidence level, twosided $t$ test). South of $25^{\circ} \mathrm{S}$, the diurnal cycle of FLCs seems to start earlier and to only depend on the distance to the coastline up to a distance of $\approx 20 \mathrm{~km}(r=0.42)$ and seems decoupled from the coast further inland $(r=-0.20)$. The region at Alexander Bay seems to be an exception, where the diurnal cycle of FLCs is similar to that of the northern regions. This may be seen as a suggestion of subregional differences in the mechanisms leading to FLC formation. The lower panel of Fig. $4 \mathrm{~b}$ shows the average FLC occurrence frequency in the three subregions as a function of the distance to the coastline that features a strong relationship, especially north of $25^{\circ} \mathrm{S}$. While this is a typical feature of coastal fog (e.g., Olivier, 1992), it serves as an additional indication that the region south of $25^{\circ} \mathrm{S}$ is not influenced by marine air masses to the same extent as regions further north.

Figure 5a shows the time of the start of the diurnal FLC cycle between 22.5 and $25^{\circ} \mathrm{S}$ in two different time periods with contrasting vertical FLC characteristics. During the season of systematically higher-level FLCs (September-November: high-FLC season), a distinct relationship between distance from the coastline and the timing of FLC occurrence is apparent up to about $60 \mathrm{~km}$ inland. During the time of lowerlevel FLCs (April, May and June: low-FLC season), this relationship is only apparent within $\approx 30 \mathrm{~km}$ of the coastline. It should be noted that the overall FLC occurrence frequency is also dependent on the distance from coastline (lower panel), and in inland regions, where no relationship between distance from coastline and time of FLC occurrence is apparent, FLC occurrence is below $5 \%$. In these regions, assessments of the statistics of the diurnal cycle are limited by the overall accuracy of the detection algorithm $(97 \%$; Andersen and Cermak, 2018), and the statistics of the diurnal cycle may be more susceptible to the influence of random misclassifications. In general, the slope of the relationship illustrated in Fig. 5a can be affected by the average advection speed, the fraction of advective FLCs and the partial contribution of random misclassifications.

\section{Conclusions and outlook}

In this study, Namib-region fog and low-cloud patterns are analyzed based on data from multiple satellite sensors as well as station measurements.

FLC occurrence along the southwestern African coastline is found to be highest close to the coastline and in general confined to the low-lying coastal plains. The seasonal cycle of satellite-derived FLC occurrence is found to have a distinct latitudinal dependence. In the Angolan regions north of $\approx 17.5^{\circ} \mathrm{S}$, FLC occurrence peaks between July and October, whereas in Namibia, between 20 and $25^{\circ}$ S, FLCs occur mostly between August and February. This pattern may be explained by a seasonal shift in the dynamic conditions that led to the inland advection of marine low clouds. On seasonal scales, the spatiotemporal FLC occurrence indicates a 


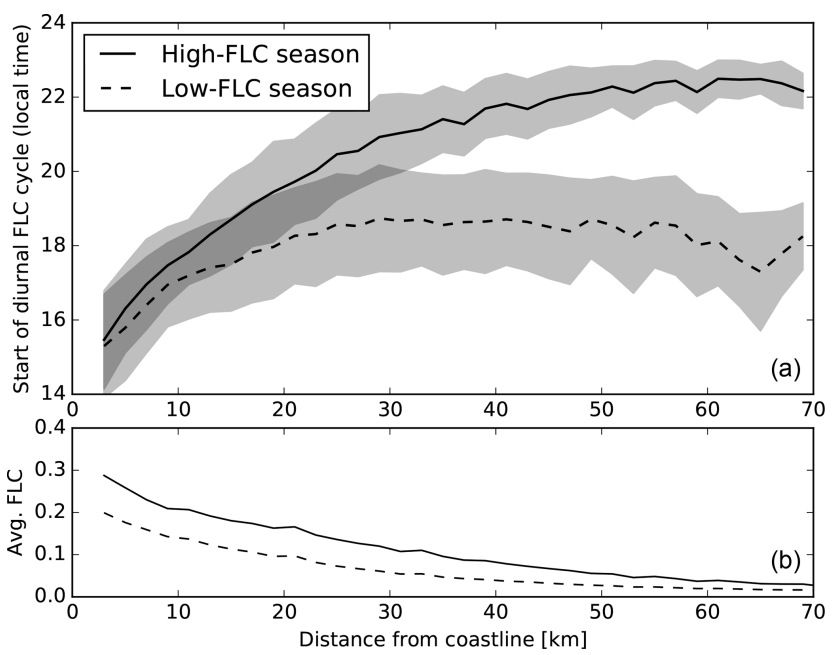

Figure 5. (a) Start of diurnal FLC cycle in the central Namib as a function of distance from the coastline. Two different seasons are shown: high-FLC season (September, October and November) and low-FLC season (April, May and June). Shaded area illustrates mean \pm 1 standard deviation. (b) Average relative FLC occurrence frequency in the two seasons. The same pixels are considered as in panel (a) and averaged in $2 \mathrm{~km}$ distance bins ( $x$ axis).

connection to the southeastern Atlantic stratocumulus cloud deck. As such, process knowledge from studies on the heavily investigated stratocumulus clouds in this region (e.g., Adebiyi and Zuidema, 2018; Andersen and Cermak, 2015; Diamond et al., 2018; Fuchs et al., 2017, 2018; Gordon et al., 2018; Painemal et al., 2014; Yuter et al., 2018) may be applicable to Namib-region FLCs, and vice versa.

Satellite-derived seasonal patterns of FLCs are compared to ground-based measurements of fog occurrence from the FogNet stations in the central Namib. While the seasonal patterns agree qualitatively and quantitatively for inland stations, they feature contrasting patterns at coastal stations. This can likely be explained by seasonal patterns in cloud-base altitude that determine whether a low-level cloud touches the ground (fog) or not. Observations from CALIPSO and SCIAMACHY suggest that, on average, clouds in coastal regions seem to be disconnected from the surface more frequently between August and February, where the satellite observations strongly overestimate station-measured ground-fog occurrence.

Coherent spatial patterns of the diurnal cycle of FLC occurrence in the Namib could be observed for the first time using the algorithm developed by Andersen and Cermak (2018). Generally, the timing of FLC occurrence seems to be tightly connected to the proximity of the coastline, where the diurnal cycle of FLCs starts systematically earlier at the coast than further inland. This is a strong indication for a dominant role of advection for the climatological patterns of FLCs in the region, contrasting the interpretation of findings from isotope analyses by Kaseke et al. (2017). In the central

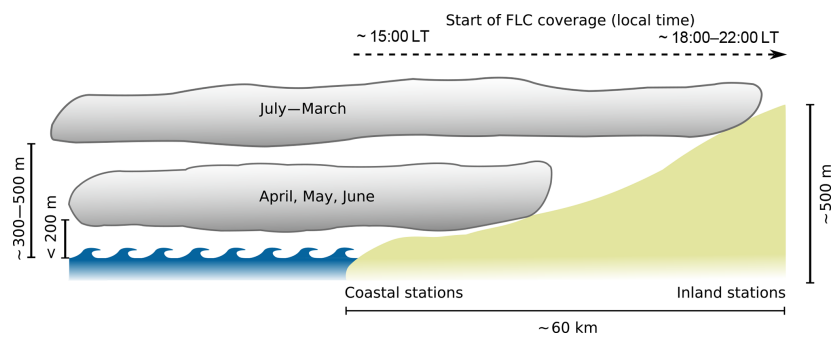

Figure 6. Schematic illustrating the observed seasonal cycle in cloud vertical characteristics and the dependence of the diurnal FLC cycle on the distance to the coastline.

Namib, the diurnal cycle of FLCs is found to start more than $2 \mathrm{~h}$ later than in most regions along the coastline. This may be caused by local advection patterns of FLCs or could be due changes in surface roughness associated with the coastparallel dunes of the Namib sand sea. The key findings regarding the seasonal and diurnal patterns of FLCs are summarized schematically in Fig. 6 and lead to a more complete view on Namib-region FLCs. The results of this study highlight the advantages of combining ground- and space-based (active and passive sensoric) measurements.

The interplay of large-scale dynamics with thermally and topographically induced local winds (Tyson and Seely, 1980; Olivier, 1992, and sources therein), (sea) surface characteristics (Olivier, 1995), radiative transfer and aerosols is likely to explain fog and low cloud occurrence and variability in the Namib desert. The exact manner, however, by which the various processes determine this complex system and its observed spatiotemporal dynamics is still unclear. Future research is thus needed to more fully understand the processes that lead to the variability in spatial patterns, overall coverage, vertical structure and life cycle of FLCs, as well their capacity to serve as a water source for ecosystems. Within the ongoing research project Namib Fog Life Cycle Analysis (NaFoLiCA), these aspects are currently studied using a combination of satellite data, ground-based measurements and numerical models.

Code and data availability. Code and data are available from the corresponding author upon reasonable request. 
Appendix A: List of acronyms

\section{A1 Station abbreviations}
Aussinanis
$\mathrm{AU}$ (inland station)
Coastal Met
$\mathrm{CM}$ (coastal station)
Conception Water
CW (coastal station)
Garnet Koppie
GK (inland station)
Gobabeb Met
GB (inland station)
Kleinberg
KB (transition station)
Marble Koppie
MK (inland station)
Saltworks
SW (coastal station)
Sophies Hoogte
SH (inland station)
Station 8
S8 (inland station)
Vogelfederberg
VF (inland station)

\section{A2 General acronyms}
a.g.l.
Above ground level
a.s.l.
Above sea level
CALIOP
Cloud-Aerosol Lidar with Orthogonal Polarization
CALIPSO
$\mathrm{CBH}$
Cloud-Aerosol Lidar and Infrared Pathfinder Satellite Observation
COT
Cloud-base height
$\mathrm{CTH}$
Cloud optical thickness
FLCs
Cloud-top height
MSG
Fog and low clouds
SACURA Semi-Analytical CloUd Retrieval Algorithm
SCIAMACHY Scanning Imaging Absorption Spectrometer for Atmospheric Chartography
SEVIRI
Spinning Enhanced Visible and Infrared Imager
SASSCAL
Southern African Science Service Centre for Climate Change and Adaptive Land Management 
Author contributions. HA and JC had the idea for the analysis. HA obtained and analyzed most of the data sets, conducted the original research and wrote the manuscript. IS and LL contributed to data analysis, and RV provided the quality controlled FogNet data. JC, IS, LL and RV contributed manuscript preparation and the interpretation of findings.

Competing interests. The authors declare that they have no conflict of interest.

Special issue statement. This article is part of the special issue "New observations and related modelling studies of the aerosolcloud-climate system in the Southeast Atlantic and southern Africa regions (ACP/AMT inter-journal SI)". It is not associated with a conference.

Acknowledgements. Funding for this study was provided by Deutsche Forschungsgemeinschaft (DFG) in the project Namib Fog Life Cycle Analysis (NaFoLiCA), CE 163/7-1. Luca Lelli has been financially supported by the European Space Agency (ESA) via the Living Planet Fellowship for the STARCLINT (STatistics of AeRosol and CLoud INTeractions) project and by the German Science Foundation (DFG) in the framework of the Transregional Collaborative Project TR 172 AC3 (ArctiC Amplification: Climate relevant Atmospheric and surfaCe processes and feedback mechanisms). We acknowledge support by the KIT-Publication Fund of the Karlsruhe Institute of Technology. The authors would like to thank the Gobabeb Research and Training Centre for access to the station measurements and gratefully acknowledge the Gobabeb maintenance team for their efforts in the field. We thank Mary Seely for her contributions in the development of FogNet. The valuable comments of two anonymous reviewers and the co-editor helped improve the original paper.

The article processing charges for this open-access publication were covered by a Research

Centre of the Helmholtz Association.

Review statement. This paper was edited by Frank Eckardt and reviewed by Stephanie Westerhuis and Jana Olivier.

\section{References}

Adebiyi, A. A. and Zuidema, P.: Low cloud cover sensitivity to biomass-burning aerosols and meteorology over the southeast Atlantic, J. Climate, 2, 4329-4346, https://doi.org/10.1175/JCLID-17-0406.1, 2018.

Andersen, H. and Cermak, J.: How thermodynamic environments control stratocumulus microphysics and interactions with aerosols, Environ. Res. Lett., 10, 24004, https://doi.org/10.1088/1748-9326/10/2/024004, 2015.

Andersen, H. and Cermak, J.: First fully diurnal fog and low cloud satellite detection reveals life cycle in the Namib, At- mos. Meas. Tech., 11, 5461-5470, https://doi.org/10.5194/amt11-5461-2018, 2018.

Azúa-Bustos, A., González-Silva, C., Mancilla, R. A., Salas, L., Gómez-Silva, B., McKay, C. P., and Vicuña, R.: Hypolithic Cyanobacteria Supported Mainly by Fog in the Coastal Range of the Atacama Desert, Microb. Ecol., 61, 568-581, https://doi.org/10.1007/s00248-010-9784-5, 2011.

Bovensmann, H., Burrows, J. P., Buchwitz, M., Frerick, J., Noël, S., Rozanov, V. V., Chance, K. V., and Goede, A. P. H.: SCIAMACHY: Mission objectives and measurement modes, J. Atmos. Sci., 56, 127-150, https://doi.org/10.1175/1520 0469(1999)056<0127:SMOAMM>2.0.CO;2, 1999.

Cermak, J.: Low clouds and fog along the South-Western African coast - Satellite-based retrieval and spatial patterns, Atmos. Res., 116, 15-21, https://doi.org/10.1016/j.atmosres.2011.02.012, 2012.

Cermak, J.: Fog and low cloud frequency and properties from active-sensor satellite data, Remote Sens.-Basel, 10, 1-7, https://doi.org/10.3390/rs10081209, 2018.

Diamond, M. S., Dobracki, A., Freitag, S., Small Griswold, J. D., Heikkila, A., Howell, S. G., Kacarab, M. E., Podolske, J. R., Saide, P. E., and Wood, R.: Time-dependent entrainment of smoke presents an observational challenge for assessing aerosolcloud interactions over the southeast Atlantic Ocean, Atmos. Chem. Phys., 18, 14623-14636, https://doi.org/10.5194/acp-1814623-2018, 2018.

Ebner, M., Miranda, T., and Roth-Nebelsick, A.: Efficient fog harvesting by Stipagrostis sabulicola (Namib dune bushman grass), J. Arid Environ., 75, 524-531, https://doi.org/10.1016/j.jaridenv.2011.01.004, 2011.

Eckardt, F., Soderberg, K., Coop, L., Muller, A., Vickery, K., Grandin, R., Jack, C., Kapalanga, T., and Henschel, J.: The nature of moisture at Gobabeb, in the central Namib Desert, J. Arid Environ., 93, 7-19, https://doi.org/10.1016/j.jaridenv.2012.01.011, 2013.

Frumau, K. F., Burkard, R., Schmid, S., Bruijnzeel, L. A., Tobón, C., and Calvo-Alvarado, J. C.: A comparison of the performance of three types of passive fog gauges under conditions of wind-driven fog and precipitation, Hydrol. Process., 25, 374 383, https://doi.org/10.1002/hyp.7884, 2011.

Fuchs, J., Cermak, J., Andersen, H., Hollmann, R., and Schwarz, K.: On the Influence of Air Mass Origin on Low-Cloud Properties in the Southeast Atlantic, J. Geophys. Res.-Atmos., 122, 1107611091, https://doi.org/10.1002/2017JD027184, 2017.

Fuchs, J., Cermak, J., and Andersen, H.: Building a cloud in the southeast Atlantic: understanding low-cloud controls based on satellite observations with machine learning, Atmos. Chem. Phys., 18, 16537-16552, https://doi.org/10.5194/acp-18-165372018, 2018.

Gordon, H., Field, P. R., Abel, S. J., Dalvi, M., Grosvenor, D. P., Hill, A. A., Johnson, B. T., Miltenberger, A. K., Yoshioka, M., and Carslaw, K. S.: Large simulated radiative effects of smoke in the south-east Atlantic, Atmos. Chem. Phys., 18, 15261-15289, https://doi.org/10.5194/acp-18-15261-2018, 2018.

Juvik, J. O. and Nullet, D.: Comments on "A Proposed Standard Fog Collector for Use in High-Elevation Regions", J. Appl. Meteorol., 34, 2108-2110, https://doi.org/10.1175/15200450(1995)034<2108:COPSFC>2.0.CO;2, 1995. 
Kaseke, K. F., Wang, L., and Seely, M. K.: Nonrainfall water origins and formation mechanisms, Science Advances, 3, e1603131, https://doi.org/10.1126/sciadv.1603131, 2017.

Kaseke, K. F., Tian, C., Wang, L., Seely, M., Vogt, R., Wassenaar, T., and Mushi, R.: Fog spatial distributions over the central namib desert - An isotope approach, Aerosol Air Qual. Res., 18, 49-61, https://doi.org/10.4209/aaqr.2017.01.0062, 2018.

Kaspar, F., Helmschrot, J., Mhanda, A., Butale, M., de Clercq, W., Kanyanga, J. K., Neto, F. O. S., Kruger, S., Castro Matsheka, M., Muche, G., Hillmann, T., Josenhans, K., Posada, R., Riede, J., Seely, M., Ribeiro, C., Kenabatho, P., Vogt, R., and Jürgens, N.: The SASSCAL contribution to climate observation, climate data management and data rescue in Southern Africa, Adv. Sci. Res., 12, 171-177, https://doi.org/10.5194/asr-12-171-2015, 2015.

Klein, S. A. and Hartmann, D. L.: The Seasonal Cycle of Low Stratiform Clouds, J. Climate, 6, 1587-1606, https://doi.org/10.1175/15200442(1993)006<1587:TSCOLS>2.0.CO;2, 1993.

Kotthaus, S., O'Connor, E., Münkel, C., Charlton-Perez, C., Haeffelin, M., Gabey, A. M., and Grimmond, C. S. B.: Recommendations for processing atmospheric attenuated backscatter profiles from Vaisala CL31 ceilometers, Atmos. Meas. Tech., 9, 37693791, https://doi.org/10.5194/amt-9-3769-2016, 2016.

Lancaster, J., Lancaster, N., and Seely, M. K.: Climate of the central Namib desert, Madoqua, 14, 5-61, 1984.

Lelli, L. and Vountas, M.: Chapter 5 - Aerosol and Cloud Bottom Altitude Covariations From Multisensor Spaceborne Measurements, in: Remote Sensing of Aerosols, Clouds, and Precipitation, edited by: Islam, T., Hu, Y., Kokhanovsky, A., and Wang, J., pp. 109-127, Elsevier, Amsterdam, the Netherlands, https://doi.org/10.1016/B978-0-12-810437-8.00005-0, 2018.

Lelli, L., Kokhanovsky, A. A., Rozanov, V. V., and Burrows, J. P.: Radiative transfer in the oxygen A-band and its application to cloud remote sensing, Atti Acc. Pel. Per. (AAPP), 89, C1V89S1P056-1-C1V89S1P056-4, https://doi.org/10.1478/C1V89S1P056, 2011.

Lelli, L., Kokhanovsky, A. A., Rozanov, V. V., Vountas, M., Sayer, A. M., and Burrows, J. P.: Seven years of global retrieval of cloud properties using space-borne data of GOME, Atmos. Meas. Tech., 5, 1551-1570, https://doi.org/10.5194/amt-5-1551-2012, 2012.

Lelli, L., Kokhanovsky, A. A., Rozanov, V. V., Vountas, M., and Burrows, J. P.: Linear trends in cloud top height from passive observations in the oxygen A-band, Atmos. Chem. Phys., 14, 56795692, https://doi.org/10.5194/acp-14-5679-2014, 2014.

Martucci, G., Milroy, C., and O’Dowd, C. D.: Detection of cloud-base height using Jenoptik CHM15K and Vaisala CL31 ceilometers, J. Atmos. Ocean. Tech., 27, 305-318, https://doi.org/10.1175/2009JTECHA1326.1, 2010.

McHugh, T. A., Morrissey, E. M., Reed, S. C., Hungate, B. A., and Schwartz, E.: Water from air: An overlooked source of moisture in arid and semiarid regions, Sci. Rep.-UK, 5, 1-6, https://doi.org/10.1038/srep13767, 2015.

Nagel, J. F.: Fog Precipitation at Swakopmund, South African Weather Bureau Newsletter, 125, 1-9, 1959.

Olivier, J.: Some spatial and temporal aspects of fog in the Namib, South African Geographer, 19, 106-126, 1992.
Olivier, J.: Spatial distribution of fog in the Namib, J. Arid Environ., 29, 129-138, https://doi.org/10.1016/S0140-1963(05)80084-9, 1995.

Olivier, J. and Stockton, P. L.: The influence of upwelling extent upon fog incidence at Lüderitz, southern Africa, Int. J. Climatol., 9, 69-75, https://doi.org/10.1002/joc.3370090106, 1989.

Painemal, D., Kato, S., and Minnis, P.: Boundary layer regulation in the southeast Atlantic cloud microphysics during the biomass burning season as seen by the A-train satellite constellation, J. Geophys. Res.-Atmos., 119, 11288-11302, https://doi.org/10.1002/2014JD022182, 2014.

Roth-Nebelsick, A., Ebner, M., Miranda, T., Gottschalk, V., Voigt, D., Gorb, S., Stegmaier, T., Sarsour, J., Linke, M., and Konrad, W.: Leaf surface structures enable the endemic Namib desert grass Stipagrostis sabulicola to irrigate itself with fog water, J. Roy. Soc., 9, 1965-74, https://doi.org/10.1098/rsif.2011.0847, 2012.

Rozanov, V. V. and Kokhanovsky, A. A.: Semianalytical cloud retrieval algorithm as applied to the cloud top altitude and the cloud geometrical thickness determination from top-of-atmosphere reflectance measurements in the oxygen A band, J. Geophys. Res., 109, 4070, https://doi.org/10.1029/2003JD004104, 2004.

Schmetz, J., Pili, P., Tjemkes, S., Just, D., Kerkmann, J., Rota, S., and Ratier, A.: An Introduction to Meteosat Second Generation (MSG), B. Am. Meteorol. Soc., 83, 977-992, https://doi.org/10.1175/BAMS-83-7-Schmetz-1, 2002.

Seely, M. K.: Irregular fog as a water source for desert dune beetles, Oecologia, 42, 213-227, https://doi.org/10.1007/BF00344858, 1979.

Seely, M. K. and Henschel, J. R.: The Climatology of Namib Fog, Proceedings, First International Conference on Fog and Fog Collection, Vancouver, Canada, 353-356, 1998.

Seely, M. K., De-Vos, M. P., and Louw, G. N.: Fog imbibition satellite fauna and unusual leaf structure in a namib desert dune plant trianthema hereroensis, S. Afr. J. Sci., 73, 169-172, 1977.

Shanyengana, E.: Exploring fog as a supplementary water source in Namibia, Atmos. Res., 64, 251-259, https://doi.org/10.1016/S0169-8095(02)00096-0, 2002.

Tyson, P. D. and Seely, M. K.: Local winds over the central Namib, S. Afr. Geogr. J., 62, 135-150, https://doi.org/10.1080/03736245.1980.10559630, 1980.

Vermeesch, P., Fenton, C. R., Kober, F., Wiggs, G. F., Bristow, C. S., and $\mathrm{Xu}, \mathrm{S}$.: Sand residence times of one million years in the Namib Sand Sea from cosmogenic nuclides, Nat. Geosci., 3, 862-865, https://doi.org/10.1038/ngeo985, 2010.

Wiegner, M., Mattis, I., Pattantyús-Ábrahám, M., Bravo-Aranda, J. A., Poltera, Y., Haefele, A., Hervo, M., Görsdorf, U., Leinweber, R., Gasteiger, J., Haeffelin, M., Wagner, F., Cermak, J., Komínková, K., Brettle, M., Münkel, C., and Pönitz, K.: Aerosol backscatter profiles from ceilometers: validation of water vapor correction in the framework of CeiLinEx2015, Atmos. Meas. Tech., 12, 471-490, https://doi.org/10.5194/amt-12-4712019, 2019.

Yuter, S. E., Hader, J. D., Miller, M. A., and Mechem, D. B.: Abrupt cloud clearing of marine stratocumulus in the subtropical southeast Atlantic, Science, 361, 697-701, https://doi.org/10.1126/science.aar5836, 2018. 